\title{
Temperature can sharpen tactile acuity
}

\author{
JOSEPH C. STEVENS \\ John B. Pierce Foundation Laboratory and Yale University, New Haven, Connecticut
}

\begin{abstract}
The spatial acuity of the skin, as measured by two-point and two-edge limens, depends on the temperature of the objects that are touched. Cooling and warming the objects caused a marked improvement (an average of $41 \%$ in six subjects) in the skin's acuity relative to thermally neutral stimulation. This improvement seems to be closely related to earlier observations that warm and cold objects placed on the skin feel heavier than do thermally neutral objects.
\end{abstract}

Students of the dermal senses owe much to the pioneer work of the German physiologist E. H. Weber $(1834,1846)$. In addition to his famous generalization regarding differential sensitivity, he invented the first measures of spatial acuity-the twopoint limen and the error of point localization. Less well known is his curious observation that concomitant cold can enhance the magnitude of pressure sensations from the skin. The present paper presents evidence that this phenomenon is more than just a curiosity and, in fact, may relate closely to the subject of spatial acuity.

Recent investigations (Stevens, 1979; Stevens \& Green, 1978b) have shown that cold objects placed on the skin do indeed feel heavier than thermally neutral objects (i.e., objects at approximately skin temperature). This "enhancement" is quite large, up to $250 \%$ or more under the right conditions, and it takes place in all areas tested so far: forehead, palm, forearm, abdomen, thigh, upper arm, and back. Warm objects can also enhance pressure sensations in some body areas (e.g., forearm) but not in others (e.g., forehead).

Early in our research on temperature enhancement, we conjectured that enhancement may represent an irresistible "cognitive" summation of the thermal sensation with the pressure sensation, even though the subject is instructed to ignore the thermal sensation. But this conjecture would appear to be wrong because it fails to explain why people sum warm sensations with pressure sensations from some body regions and not from others. Instead, we looked to a more peripheral explanation. Dermal receptors responsive to mechanical stimulation are very often responsive also to cooling and, apparently less often, to warming. The skin also contains polymodal nociceptors that show little stimulus selectivity.

This research was supported by NIH Grant R01NS15419. The author thanks Janet Hooper for technical assistance. Requests for reprints should be addressed to Joseph C. Stevens, John B. Pierce Foundation Laboratory, 290 Congress Avenue, New Haven, Connecticut 06519.
In the course of exploring thermal enhancement over the body surface (Stevens, 1979), it became clear that, irrespective of temperature effects, some regions of the body are more sensitive to pressure than others; that is, the same circular objects (area= $12.6 \mathrm{~cm}^{2}$; mass $=21,45$, and $105 \mathrm{~g}$ ) were judged to feel heavier on, say, the palm than on the back. The rank order of weight sensitivity of the body regions tested turned out to correlate almost perfectly with the rank order for the two-point limen and point localization, as measured by Weinstein (1968). There was, however, no correlation with two other measures of dermal sensitivity, namely, punctate pressure (Weinstein, 1968) and vibration $(200 \mathrm{~Hz})$ threshold (Wilska, 1954). Although he gave no quantitative data, Weber reported as early as 1834 , in De Tactu, a correlation between weight sensitivity and acuity: "Weights arouse a stronger pressure sensation in those parts of the skin where our tactile acuity for the separation of the compass legs is best" (Weber, 1978, p. 121).

The high correlation between nonpunctiform sensitivity and spatial acuity points to the possibility that both may be mediated by the same receptor systemone having little to do with vibrotactile or punctate sensitivity and perhaps more to do with the perception of edges and gradients. Such a receptor system was recently postulated by Verrillo (1979). If acuity and weight perception are mediated by the same receptor network, then it is reasonable to hypothesize that temperature may influence acuity as well as apparent weight. The present paper offers evidence that this is so and that both warm and cold can enhance tactile acuity by a surprising amount.

It should be pointed out that it is mainly the object (stimulator) temperature that matters here. Some effects of skin temperature have been assessed elsewhere. Cooling the skin depresses sensitivity to gaps (Mackworth, 1953; Mills, 1956; Provins \& Morton, 1960 ), to punctate pressure sensitivity (Stevens, Green, \& Krimsley, 1977), to roughness (Green, Lederman, \& Stevens, 1979), and to vibrotactile stimulation (Green, 1977a; Weitz, 1941). Warming the 
skin to $36^{\circ}-37^{\circ} \mathrm{C}$ enhances sensitivity to high-frequency vibration; the study of warming on other sensitivity measures is too limited to be conclusive, but, if anything, there seems to be slight improvement under mild warming. A question of potential interest is how skin and object temperature may interact to establish acuity, but for the time being our measurements are confined to skin temperature at neutral ambient conditions.

\section{METHOD}

Spatial acuity was measured in two young women and four young men. All were naive as to the purpose of the experiment. Three subjects were tested for two-point limen, and the other three, for a gap detection (two-edge threshold). Each subject was tested four times on 4 separate days. The site of stimulation was the volar forearm, one of the regions known to give good cold and warm enhancement of pressure.

The method used was a triple-track Békésy tracking procedure, one track each for cold, warm, and neutral stimulators. By this procedure, the distance between the points or edges was varied in 2-mm steps, either increased when the subject's previous response had been "one" or decreased when the previous response had been "two." The experimenter moved from one track to another from trial to trial, in no fixed order but with care to prevent general heating or cooling of the skin. The procedure was continued until at least 13 transition distances were obtained on each track. The first 3 transitions were not counted; the threshold was defined as the average of the remaining transitions (never fewer than 10). Applications lasted $2 \mathrm{sec}$ each, and there were, altogether, from about 75 to 125 applications per session. Sessions lasted between 35 and $50 \mathrm{~min}$.

This psychophysical procedure has two possible advantages. The first is that it is possible to stimulate rapidly without greatly affecting resting skin temperature (in addition, the exact locus of stimulation was varied within an area of about $15 \mathrm{~cm}^{2}$ ). The $\mathrm{sec}-$ ond is that extraneous factors such as deterioration of attention or shift in judgmental criterion can be expected to affect the three tracks in much the same way and thereby promote the sensitivity of the measurement of the effects of temperature.

The stimulators were commercial metallic calipers (roll-track) adapted to the purpose of the experiment. For two-point limens, the points of the calipers were filed to a smooth surface of about $1 \mathrm{~mm}^{2}$. For two-edge limens, edges were soldered to the calipers. These edges were $2 \mathrm{~mm}$ thick and $25 \mathrm{~mm}$ wide. They added considerable mass to the stimulation. When applied to a balance in the same fashion as was done in application to the skin, the force measured $35 \mathrm{~g}$ for the two points and $60 \mathrm{~g}$ for the two edges. The two points or edges were always applied at right angles to the long axis of the arm.

The temperature of the stimulators was controlled by regulated water baths or by ice water. For the two-point stimulators, the three bath temperatures were $0^{\circ}, 33^{\circ}$, and $60^{\circ} \mathrm{C}$; for the two-edge stimulators, the temperatures were $0^{\circ}, 33^{\circ}$, and $50^{\circ} \mathrm{C}$. However, by the time the stimulators were removed from the bath, dried, and applied to the skin, their temperatures changed, especially from evaporative cooling. To assess the change, a fine fastresponding thermocouple was fixed by a fine-gauge wire to the surface of the stimulator. So measured, for the two-point stimulators, the temperature of the warm stimulator averaged about $43^{\circ} \mathrm{C}$ just before application, that of the "neutral" stimulator averaged $29.5^{\circ} \mathrm{C}$, and that of the cold averaged $4^{\circ} \mathrm{C}$. (Since normal resting temperature of the forearm was about $32.5^{\circ} \mathrm{C}$, the "neutral" stimulator was actually slightly cooler than the skin.) For the two-edge stimulators, the warm and neutral temperatures just before stimulation were also about $43^{\circ}$ and $29.5^{\circ} \mathrm{C}$; the cold stimulator, however, changed to about $.75^{\circ} \mathrm{C}$, rather than to $4^{\circ} \mathrm{C}$, owing to the greater mass of the edges.

\section{RESULTS}

Table 1 shows the mean threshold for each subject under each thermal condition. It also shows the percentage improvement in acuity that is achieved by warming or cooling and the associated statistical significance as determined by $t$ tests based on combined data from the four sessions. Although the improvement in acuity varied considerably from one subject to another, the mean improvement came to $41 \%$, generally at high levels of statistical confidence. (The thermal conditions were such that warming and cooling had approximately the same magnitude of effect.) Even single test sessions gave statistically significant differences in 33 of $48 \mathrm{t}$ tests (6 subjects $\times 4$ sessions $\times 2$ temperatures), often at high confidence levels. Hence, the thermal effect on acuity would seem to be robust.

The results for Subject J.M. deserve comment. He consistently showed a small thermal effect that was statistically significant for cooling but not for heating. When we first began to test him, he consistently gave two-edge thresholds in the neighborhood of $50 \mathrm{~mm}$ and statistically nonsignificant effects of cooling and heating. To bring him more or less into line with the other subjects, we then gave him experience on a forced-choice staircase without feedback (i.e., on each trial, the subject was stimulated by either one or two points, and his task was to decide which). The result was that his subsequently determined limens without forced choice fell to about half their original values. Even then, however, for whatever reason, he showed smaller thermal effects than the other subjects, so that personal criterion alone would seem insufficient to explain individual differences.

\section{DISCUSSION}

Why does object temperature sharpen acuity? One obvious conjecture is that two dimensions of experience, namely, touch and warmth or cold, give more information about separation than does one alone. In fact, this is probably incorrect as a general explanation. In the first place, temperature provides an unreliable sensation in cases of tiny areas of stimulation, as anyone who has ever "spot mapped" the arm knows. For example, measurements by Strughold and Porz (1931; see also Stevens \& Green, 1978a) yielded spot densities for the forearm of only $.24 \mathrm{~cm}^{-2}$ (warmth) and $7 \mathrm{~cm}^{-2}$ (cold).

The two-point stimuli aroused thermal sensations more often than this, but not always and frequently very weakly. On the other hand, the edges, whose 
Table 1

Mean Two-Point or Two-Edge Limen, Percentage by Which Cold or Warm Improved the Limen re Neutral, and Associated Levels of Statistical Significance $(p<)$ as Determined by $t$ Tests for Each of Six Subjects

\begin{tabular}{lccccccc}
\hline $\begin{array}{l}\text { Sub- } \\
\text { ject }\end{array}$ & $\begin{array}{c}\text { Neu- } \\
\text { tral }\end{array}$ & Cold & $\begin{array}{c}\text { Improve- } \\
\text { ment }\end{array}$ & $\mathrm{p}<$ & Warm $\begin{array}{c}\text { Improve- } \\
\text { ment }\end{array}$ & $\mathrm{p}<$ \\
\hline \multicolumn{6}{c}{ Two-Point Limen (in Millimeters) } \\
M.C. & 31.9 & 20.2 & 57.9 & $10^{-9}$ & 12.8 & 149 & $10^{-9}$ \\
E.N. & 32.4 & 29.0 & 11.7 & $10^{-7}$ & 29.4 & 10.2 & $10^{-5}$ \\
T.B. & 15.2 & 10.9 & 39.4 & $10^{-7}$ & 12.0 & 26.7 & $10^{-4}$ \\
\multicolumn{8}{c}{ Two-Edge Limen (in Millimeters) } \\
L.N. & 23.2 & 20.4 & 13.7 & $10^{-8}$ & 22.1 & 4.98 & .005 \\
N.T. & 14.4 & 7.54 & 91.0 & $10^{-9}$ & 7.94 & 81.4 & $10^{-9}$ \\
J.M. & 26.5 & 24.5 & 8.2 & .0003 & 25.9 & 2.3 & n.s. \\
\hline
\end{tabular}

contact areas were 50 times larger than the points, because of the great effectiveness of spatial summation in the thermal senses (Stevens \& Marks, 1971; Stevens \& Marks, 1979; Stevens, Marks, \& Simonson, 1974), aroused fairly strong thermal sensations on a reliable basis. If saliency of the temperature sensation were really the deciding factor, one would expect a much greater improvement on the two-edge limen than on the two-point limen. Table 1 provides no encouraging evidence for that hypothesis.

There is another, more serious, difficulty with the theory. Cain (1973) showed that the warmth sense has, at best, only a feeble capacity for conveying information about the spatial properties of stimulation. It was, for example, impossible to measure the analog of the two-edge limen with infrared fields because, no matter how far the two fields were separated on the back, they aroused a fused, single image. Vendrik and Eijkman (1968) got similar results for the arm-separations as large as $15 \mathrm{~cm}$ were undetectable. Localization is also extremely unreliable, the average subject frequently confusing even ventral and dorsal presentations (Cain, 1973). Other studies confirm an overall poorness of thermal localization as compared with tactile localization (Dimmick, 1915; Gelhorn, Mehlman, \& Kaplan, 1938; Nathan \& Rice, 1966; Simmel \& Shapiro, 1969). Even at fairly high levels of warmth stimulation, subjects make large mistakes (Taus, Stevens, \& Marks, 1975). Although less is known about the spatial properties of cold, they too are probably unimpressive. Stevens and Marks (1979), for example, found that subjects almost never noticed size differences between small $\left(2 \mathrm{~cm}^{2}\right)$ and large $\left(20 \mathrm{~cm}^{2}\right)$ areas of cold stimulation under conditions that eliminated cues from mechanical stimulation.

Every experience gives the false impression that our thermal sensations are well localized. That is probably because, when we touch objects, they arouse mechanical and thermal sensations concomitantly. In some ingenious experiments involving dis- parities between the loci of mechanical and thermal stimulation, Green (1977b) showed that the touch sense determines where the thermal sensation is localized subjectively.

An alternative possible explanation for the thermal effects might be that, since warmth and cold enhance pressure sensation, the thermal effect might operate by increasing the neural traffic from the mechanoreceptors that mediate acuity, in much the way that warmth and cold enhance the degree of pressure sensation. That the warm and cold two-point and twoedge stimulators actually felt heavier than the neutral ones was certainly not obvious to casual observation, and indeed it has proved difficult to demonstrate thermal intensification of heaviness using very small areas of stimulation (Jones, Singer, \& Twelker, 1962; Stevens \& Green, 1978b). Moreover, it is unclear why a simple increase in neural response should increase acuity. A study by Phillips (1980) revealed no obvious dependence of acuity on the force of application. Increased force would obviously increase neural activity, although the picture is complicated because increased force could also affect the skin gradients produced by the stimulators and thereby alter the resulting neural pattern.

I am indebted to Barry G. Green for suggesting another, more plausible explanation. This is that the two-point and two-edge acuity may be determined by lateral gradients of mechanoreceptor activity across the skin and that these gradients can be sharpened by brief local thermal stimulation, as illustrated in Figure 1. Since lateral thermal gradients for transient stimulations would be small compared with the mechanical gradients, the resulting neural pattern would become more distinctly dual due to localized

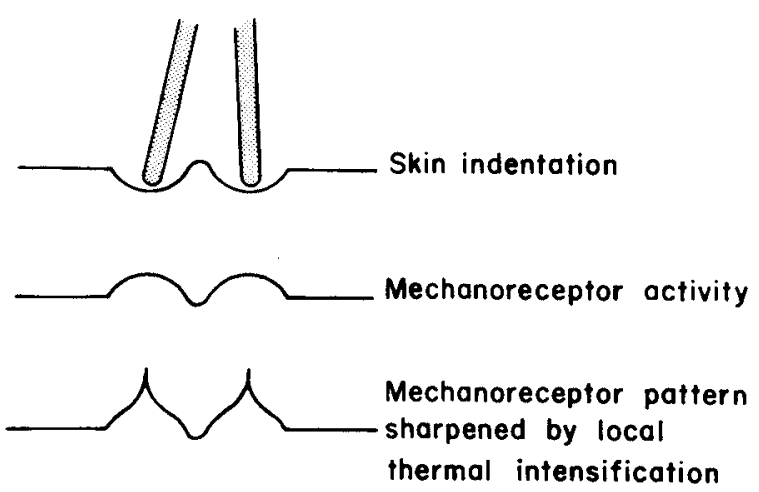

Figure 1. A hypothetical illustration of how thermal enhancement of mechanoreceptor activity could serve to sharpen tactlle acuity. The points of the stimulator cause rather broad gradients of skin stretching, and these could be reflected by broad gradients of mechanoreceptor discharge. However, for brief stimulations, the thermal gradients are sharp, so their effect on the mechanoreceptors is very locallzed. The net effect is to sharpen the mechanoreceptor pattern of duality. 
thermal intensification of mechanoreceptive activity. Whatever the mechanism may prove to be, it is clear that temperature can serve to sharpen our appreciation of the tactile world. Most of the objects that in everyday life we touch and handle are at temperatures below (typically) or above that of the skin. Hence, nearly the whole tactile world would in theory come into sharper focus by means of joint operations of mechanical and thermal stimuli. On this view, the imperfect stimulus selectivity shown by typical mechanoreceptors is no mere epiphenomenon but, rather, has genuine functional significance to perception by touch. It is even possible that the thermal dimension may be an important factor to be taken into consideration in the development of tactile communication systems for the blind and deaf.

Much remains to be learned in future experiments. One basic problem touched on above is how skin temperature and object temperature might interact. For example, is it possible that cold enhancement of acuity may be strengthened further if the skin is warmed? Another problem is to learn whether thermal sharpening takes place generally over the skin surface, especially in the hands and fingers. Still another problem is to explore how other measures of tactile acuity-such as point localization and roughness-will reflect object temperature. There is also the problem of the large individual differences in the effect. And finally, there is the question of how simultaneous warming and cooling might influence tactile acuity.

In conclusion, the results of the present experiment underscore an earlier observation (Stevens, 1980) that, in physiological and psychological research on the dermal senses, stimulation has tended to be unrealistically unidimensional. Yet everyday stimulation of the skin is nearly always multidimensional, and dermal receptors commonly show imperfect stimulus selectivity. The possible functional significance of such facts deserves examination.

\section{REFERENCES}

CAIN, W. S. Spatial discrimination of cutaneous warmth. American Journal of Psychology, 1973, 86, 169-181.

Dimmick, F. L. Minor studies from the psychological laboratory of Cornell University. American Journal of Psychology, 1915, 26, 142-150.

Gelhorn, E., Mehlman, J., \& Kaplan, M. Contribution to problems of cutaneous localization in man. Archives of Neurology and Psychiatry, 1938, 39, 327-332.

GreEN, B. G. The effect of skin temperature on vibrotactile sensitivity. Perception \& Psychophysics, 1977, 21, 243-248. (a)

Green, B. G. Localization of thermal sensation: An illusion and synthetic heat. Perception \& Psychophysics, 1977, 22, 331-337. (b)

Green, B. G., Lederman, S. J., \& Stevens, J. C. The effect of skin temperature on the perception of roughness. Sensory Processes, 1979, 3, 327-333.
Jones, F. N., Singer, D., \& Twelker, P. A. Interactions among the somesthetic senses in judgments of subjective magnitude. Journal of Experimental Psychology, 1962, 64, 103-109.

Mackworth, N. H. Finger numbness in very cold winds. Journal of Applied Physiology, 1953, 5, 533-543.

Mills, A. W. Finger numbness and skin temperature. Journal of Applied Physiology, 1956, 9, 447-450.

Nathan, P. W., \& Rice, R. C. The localization of warm stimuli. Neurology, 1966, 16, 533-540.

Phillips, J. R. Tactile spatial resolution. Doctoral dissertation, University of Melbourne, 1980.

Provins, K. A., \& Morton, R. Tactile discrimination and skin temperature. Journal of Applied Physiology, 1960, 15, 155-160.

Simmell, M. L., \& Shapiro, A. The localization of non-tactile thermal sensations. Psychophysiology, 1969, 5, 415-425.

Stevens, J. C. Thermal intensification of touch sensation: Further extensions of the Weber phenomenon. Sensory Processes, $1979,3,240-248$.

STEvENS, J. C. Thermo-tactile interactions: Some influences of temperature on touch. In D. Kenshalo (Ed.), Sensory functions of the skin of humans. New York: Plenum, 1980.

Stevens, J. C., \& Green, B. G. History of research on feeling. In E. C. Carterette \& M. P. Friedman (Eds.), Handbook of perception (Vol. 6B): Feeling and hurting. New York: Academic Press, 1978. (a)

Stevens, J. C., \& Green, B. G. Temperature-touch interactions: Weber's phenomenon revisited. Sensory Processes, 1978, 2, 206-219. (b)

Stevens, J. C., Green, B. G., \& Krimsley, A. S. Punctate pressure sensitivity: Effect of skin temperature. Sensory Processes, 1977, 1, 238-243.

Stevens, J. C., \& Marks, L. E. Spatial summation and the dynamics of warmth sensation. Perception \& Psychophysics, 1971, 9, 391-398.

Stevens, J. C., \& Marks, L. E. Spatial summation of cold. Physiology \& Behavior, 1979, 22, 541-547.

Stevens, J. C., Marks, L. E., \& Simonson, D. C. Regional sensitivity and spatial summation in the warmth sense. Physiology \& Behavior, 1974, 13, 825-836.

Strughold, H., \& Porz, R. Die Dichte der Kaltpunkte auf der Haut des menschlichen Körpers. Zeitschrift für Biologie, 1931, 91, 563-571.

Taus, R. H., Stevens, J. C., \& Marks, L. E. Spatial localization of warmth. Perception \& Psychophysics, 1975, 17, 194-196.

Vendrik, A. J. H., \& EiJkman, E. G. Psychophysical properties which can be related to electrophysiological data. In $D$. R. Kenshalo (Ed.), The skin senses. Springfield, Ill: Thomas, 1968.

Verrilto, R. T. The effect of surface gradients on vibrotactile thresholds. Sensory Processes, 1979, 3, 27-36.

WEBER, E. H. De pulsu, resorptione, auditu, et tactu. Leipzig: Koehler, 1834.

WEBER, E. H. Der Tastsinn und das Gemeingefühl. In R. Wagner (Ed.), Handwörterbuch der Physiologie (Vol. 3). Braunschweig: Vieweg, 1846.

WEBER, E. H. The sense of touch (English translations of De tactu and Der Tastsinn by H. E. Ross \& D. J. Murray). London: Academic Press, 1978.

WEINSTEIN, S. Intensive and extensive aspects of tactile sensitivity as a function of body part, sex, and laterality. In D. R. Kenshalo (Ed.), The skin senses. Springfield, Ill: Thomas, 1968.

WEITz, J. Vibratory sensitivity as a function of skin temperature. Journal of Experimental Psychology, 1941, 28, 21-36.

WILSKA, A. On the vibrational sensitivity in different regions of the body. Acta Physiologica Scandinavica, 1954, 31, 285-289.

(Manuscript received March 1, 1982; accepted for publication March 11, 1982.) 